\title{
CHRONIC HANDICAP IN CHILDHOOD
}

\author{
R. G. Mitchell, M.D., F.R.C.P.(Edin.), D.C.H. \\ Professor of Child Health, University of Aberdeen
}

Chronic handicap is a major challenge to present-day paediatrics in Britain. The change in the paittern of child disease in western countries is well known-the decline in mortality of both infants and children: the virtual eradication of serious acute infections such as tuberculosis, diphtheria and poliomyelitis: the diminishing incidence of acute rheumatism: and the control of the common infectious diseases. These changes have brought great improvements in the health of children ibut they have been offset in part by increasing prominence of the conditions causing continuing disability. There are a number of reasons why this is so. Antibiotic therapy has allowed the survival of handicapped children who would formerly have died in infancy from intercurrent infection: advances in surgery can correct malformation which would otherwise be lethal-but the child thus saved is often not completely normal: there may be an absolute increase in some conditions such as asthma, which in its severe manifestations can be crippling and at best interferes with normal education and social activities. Although these and other chronic disabilities affect a comparatively small section of the child population, they claim a disproportionately large share of medical care, while they make great demands on the community in terms of buildings, transport and other facilities, skilled attendants and therapists, and special educational arrangements.

Chronic handicap in childhood is a subject of vast proportions and in this brief review only a few facets which are of current interest to us in Aberdeen will be considered in any detail.

\section{Principal Causes of Chronic Handicap}

Almost any chronic disorder in childhood may constitute a handicap and conversely few conditions need be a handicap if they are of sufficiently mild degree. The extent to which a condition causes handicap depends on many things, such as the personality characteristics of the child, the environment in which he lives and the demands that society makes on him. Because the concept of the handicapped child is thus so wide, no accurate information on incidence is available, since what is considered a handicap will vary not only from child to child but also from observer to observer and $\frac{\overline{ }}{\bar{D}}$ from community to community. In the United States, it has been estimated that about 23 per cent of children under 17 years have a chronic of disability of some sort, but that only one-tenth $\vec{\circ}$ of these, representing approximately 2 per $\vec{\exists}$ cent of all children, have physical handicap $\vec{\sigma}$ sufficient to limit them severely in play $\frac{}{0}$ or school work or both (Talbot, 1965). The registers of handicap now being maintained by local authority health departments will help to fill gaps in the broad picture of of handicap in Britain, but because of the difficulties in definition mentioned, no more $\underset{\infty}{\stackrel{D}{0}}$ than a crude estimate of incidence is likely 을 to be obtained in this way. The categories used by education authorities for assessing a child's needs give a general classification which is useful for some purposes. Eleven kinds of handi- $\vec{\varphi}$ capped child are listed as follows:-(1) blinde o (2) partially sighted; (3) deaf; (4) partially dear. (5) delicate; (6) diabetic; (7) educationally suk6 normal; (8) epileptic; (9) maladjusted; (10) physically handicapped; (11) those with a speech disorder. Many children would, of $\stackrel{\circ}{\odot}$ course, fall into more than one category and such a classification system is for administrative convenience rather than of any clinical or scientific value. The relative numerical importance of the various kinds of handicap has changed with the changing pattern of childhood morbidity and some categories formerly of outstanding importance are now insignificant. Thus blindness has greatly diminished as a major problem in childhood, only about 3 per cent of the 100,000 blind people in Britain being under 14 years of age (Kershaw, 1961), and the number is likely to become even smaller. The decline in tuberculosis, chronic pyogenic infection, and other debilitating diseases has rendered the $N$ general category "delicate child" less necessary N though it may still be useful in obtaining con- N valescence or holidays for children who are poorly nourished or low in resistance to infections. "Maladjusted" is an administrative term $\stackrel{0}{\mathbb{D}}$ which is likely to be used less often as knowl- $\stackrel{?}{+}$ edge of child psychology and psychiatry be- 0 comes more general and at the same time more precise. 
For present purposes handicapping disorders may be considered as falling into three large groups, viz.: (1) neurological and psychiatric disorders including blindness and deafness; (2) cardio-respiratory disorders; (3) other handicapping conditions.

\section{Neurological and Psychiatric Disorders}

Within this area of handicap there are three broad categories - the psychological and psychotic disorders which constitute a special and important form of handicap but will not be considered further here: the syndromes of cerebral dysfunction: and the myelomeningocele/hydrocephalus group of malformations. Though these categories are very different in many ways, they share a common origin in the central nervous system: they often overlap to a considerable extent: and there may be diagnostic difficulties in differentiating between them.

\section{Syndromes of Cerebral Dysfunction}

A major component of the total problem of chronic handicap is the group of related disorders termed the syndromes of cerebral dysfunction (Denhoff and Robinault, 1960). These include mental subnormality, cerebral palsy, epilepsy, sensory handicap and disorders of behaviour. Any of these manifestations may occur in uncomplicated form but more often they occur together in various combinations. For administrative convenience it is usual to designate the syndrome by its most prominent feature. Thus a spastic child may also be intellectually retarded and have sensory difficulties: a child considered to be simply mentally subnormal may be disproportionately incoordinate due to co-existing cerebral palsy: an epileptic child may be hyperkinetic in addition: and so on in almost infinite variety. Mental subnormality constitutes the greatest single handicap to the growing child and is usually considered the most important manifestation of cerebral dysfunction, so that children classed as mentally subnormal form the largest group of handicapped children, many of them of course having other disabilities as well. Those whose Intelligence Quotients lie in the 55 to 70 range are considered educationally subnormal but capable of deriving benefit from education in special classes or schools, whereas those with I.Q. less than 55 (severely subnormal) are unsuitable for education but some may be trained in the simple activities of everyday life. Even the most severely handicapped children can often profit from intensive functional training, and may achieve a degree of self-help which appreciably reduces the physical burden of attending to their needs (Johnson, Gove and Ostermeier, 1963). The choice of I.Q. 55 as the dividing line between subnormality and severe subnormality is purely arbitrary and not universally accepted but it does broadly separate the group which is mainly sub-cultural in origin from the more severe types in which there is usually developmental or acquired abnormality of the brain.

In assessing the extent to which a child is physically handicapped, it has been found useful to grade the total physical disability on a simple three-point scale (Mitchell, 1961; Ingram, Jameson, Errington and Mitchell, 1964) but fuli assessment must of course include detailed analysis of each component of the syndrome, not only defining the clinically manifest disabilities but also carefully testing for disordered function which may not be apparent to casual observation. Particular attention should be paid to minor degrees of motor abnormality, which may account for clumsy or awkward behaviour, to the possibility of unsuspected deafness or visual difficulty, to speech disorders and to perceptual and visuomotor defects. These last are especially likely to be present when the child has a spastic type of motor disability (Abercrombie 1964) but many occur without associated motor disorder.

\section{Minimal Cerebral Dysfunction}

The term "brain damaged" has been widely used in the past, especially by psychologists, to describe children with such characteristics as hyperkinetic and antisocial behaviour, distractibility, short attention span and lability of mood, with or 'without motor awkwardness. The extent of cerebral damage in such children cannot be inferred from the severity of the behaviour disturbance, however, and the concept of "brain damage" is therefore not the same as the fact of damage to the brain (Birch 1964). In consequence, the use of the phrase "minimal cerebral damage" to describe slight degrees of disturbed behaviour is liable to misinterpretation and it should be abandoned (Bax and MacKeith, 1963). Children with minor manifestations of disordered cerebral function may be described briefly as having "minimal cerebral dysfunction" when their disability either is not of such severity as to be clearly due to one of the defined syndromes of cerebral dysfunction or is too complex for precise diagnosis. It will be apparent that the term does not define a distinct entity but it has proved useful in focus- 
ing attention on a heterogeneous group of disabilities often unrecognised or misdiagnosed, and affecting as many as 5 per cent of the general school population (Paine, 1966).

What is considered as "minimal cerebral dysfunction" depends to a considerable extent on the skill and experience of the examiner and on the sophistication of the methods he uses. Thus, for example, slight degrees of cerebral palsy causing clumsy behaviour may escape recognition by a doctor unfamiliar with the vagaries of motor disability and yet be readily diagnosed by an experienced paediatrician. Such a disorder should be described as a slight degree of cerebral palsy and not as "clumsiness due to minimal cerebral dysfunction" but difficulty in definition arises in the borderland where the least degree of cerebral palsy is indistinguishable from the maximum amount of awkwardness acceptable as normal (Mitchell, 1961). Clumsiness due to more complex disorders such as various forms of apraxia and agnosia (Gubbay, Ellis, Walton and Court, 1965) may create diagnostic difficulties for the paediatrician and require the special knowledge and technique of the paediatric neurologist to elucidate it. Disordered perception as a cause of educational failure in an apparently normal child may go unrecognised by teachers and doctors alike until revealed by a specially trained psychologist (Hatton, 1966). Some disturbances of behaviour may defy all attempts at definition because available methods are not adequate, for example, to distinguish between neurological and psychological components.

In any of these situations, and especially when several specific abnormalities exist together, the recognition that there is "minimal cerebral dysfunction" may be all that is possible in the circumstances. The term is of some use, therefore, and will be especially valuable if it leads to general recognition that minimal disorders of cerebral function can cause difficulty, such as clumsiness, apparently of minor degree and yet causing disproportionate handicap, or educational difficulty apparently unrelated to neurological abnormality, such as backwardness in reading or spelling. Minimal cerebral dysfunction should never be considered as more than a provisional diagnosis, however, and must not be used as a general category for slight degrees of recognisable syndromes of cerebral dysfunction, which are better classified according to the syndrome present, regardless of severity. Every attempi should be made to define the disability precisely and to determine its cause if possible.
Causes and Prevention of Neurological Handicap

The origins of cerebral syndromes are almost as complex as the disabilities themselves. Thus genetic or chromosomal anomalies may play a part or adverse environmental conditions in utero may operate, or the two may interact to produce an abnormal brain. In our present state of knowledge, it is not possible to prevent the defective development of the central nervous system which is responsible for so many cases of cerebral dysfunction, but cerebral damage by potentially preventable agents such as perinatal hypoxia is responsible for a substantial proportion of neurological disabilities while others may be caused by infective, vascular or traumatic lesions of the brain in early childhood. Greater understanding of the mechanisms of brain damage is essential for the informed approach to prevention which must be the ultimate objective.

Many of the causes of chronic disability which operate in the newborn period arise in infants of low birth weight. For example, the 1958 British Perinatal Mortality Survey (Butler and Bonham, 1963) showed that the respiratory distress syndrome accounted for 37.5 per cent of early neonatal deaths of infants weighing 1,001 to $2,500 \mathrm{~g}$. at birth but for only 8.3 pef cent of those weighing more than $2,500 \mathrm{~g}$. In this syndrome absence of pulmonary surfaceactive material (surfactant) leads to underventilation and circulatory disturbances in the lungs (Strang, 1965) and the consequent hypoxia is an important cause of permanent brain damage in surviving infants. Oxygen lack may also result from periods of respiratory arrest. Short episodes of apnoea of only a few seconds' duration are common in small premature infants but respiratory arrest lasting for more than half a minute is of grave prognostic significance. In such attacks the infant becomes deeply cyanosed and the arterial oxygen tension has been shown to fall to dangerously low levels within one minute of onset (Reid and Tunstall, 1965). Respiration sometimes starts again spontaneously or following peripheral stimulation but the infant may have sustained damage to the nervous system during the period of hypoxia (McDonald, 1963). Placing the infant in oxygen may diminish the rate of fall of the arterial oxygen by utilising the phenomenon of apnoeic oxygenation (Reid, Tunstall and Mitchell, 1966) but more vigorous measures may be necessary if dangerous hypoxia is to be avoided. Current work in Aberdeen and 
elsewhere indicates that intermittent positivepressure ventilation can play a decisive role in preventing damaging hypoxia in respiratory disturbances of newborn infants, and it is now accepted that, given adequate nursing and biochemical facilities, mechanically assisted respiration is a practical therapeutic measure which need not, and indeed should not, be reserved for the desperate situation (Reid and Tunstall, 1966), for its greatest potential value lies in preventing the arterial oxygen tension from falling below a minimum safe level. This and other therapeutic methods currently being tested hold out hope of preventing persisting neurological disability in at least some infants of low birth weight, though it must be remembered that in some cases the brain may be congenitally maldeveloped while in others damaging intraventricular haemorrhage may have occurred before therapeutic measures can succeed (Mitchell, 1965).

Extrapulmonary infection is a less important cause of death in the newborn period than formerly, accounting for only 1 per cent of early neonatal deaths (Butler and Bonham, 1963) but meningitis in early infancy remains an important antecedent of neurological handicap as do some of the complications of septicaemia, such as hypernatraemic dehydration (Harrison and Finberg, 1959). In a survey in North-east Scotland, Galloway (1962, 1966) found neurological sequelae, mainly intellectual impairment or deafness, in 17.5 per cent of 251 survivors of purulent meningitis in early life. This figure accords well with the findings of earlier surveys (Galloway, 1966) and with Jackson's (1965) estimate of the incidence as somewhere between 5 and 26 per cent, based on analysis of recent studies in England and America. It indicates that, despite advances in therapy, meningitis is still a major cause of cerebral damage.

Other potentially damaging agents occurring in the newbornn infant, and especially in those of low birth weight, are biochemically disturbances such as hypoglycaemia and hyperbilirubinaemia. Careful clinical observations with f reque $\mathrm{nt}$ biochemical determinations and prompt correction should prevent the more severe degrees of biochemical disturbance from occurring. There is a general relationship between the level of indirect bilirubin in the plasma of the newborn infant and later cerebral dysfunction (Hyman, Keaster, Hanson, Harris, Sedgwick and Wright, 1965), but it is not known to what extent moderate hyperbilirubinaemia, insufficient to cause clinical signs of bilirubin encephalopathy, is responsible for subsequent disability.

The precise relationship of low blood glucose concentrations to neurological handicap is not yet clear but there is now no doubt that neonatal hypoglycaemia can cause brain damage (Brown and Wallis, 1963). On the other hand, blood glucose levels which would be considered ahnormally low in adults frequently occur in newborn infants without symptoms or apparent sequelae. Infants who have grown poorly in utero are especially prone to develop very low levels of blood glucose in the first few days (Neligan, Robson and Watson, 1963) and the data of Wharton and Bower (1965) suggest that such infants are likely to suffer brain damage in consequence. The neonatal fall in blood sugar can be minimised by ensuring an adequate caloric intake from the first day after birth (Smallpiece and Davies, 1964; Russell and McKay, 1966) though the volume of each feed must be carefully regulated since immediate feeding with large amounts of milk carries a high risk of inhalation and death (Wharton and Bower, 1965). Experience in Aberdeen suggests that if possible a minimum intake of about 30 calories per $\mathrm{kg}$. of body weight should be achieved during the second day of life, rising to about 50 cals. $/ \mathrm{kg}$. on the third day, and that these amounts can be supplied in volumes well tolerated by small infants (Russell and McKay, 1966).

The studies of Drillien (1964), McDonald (1962) and many others have shown that a high proportion of small premature infants sustain neurological damage and, with higher survival rates among such infants, it may be anticipated that the complications of prematurity will continue to bulk large among the antecedents of handicap in childhood. There is increasing realisation, however, that "premature" infants do not form a homogeneous group and the World Health Organisation has recognised this difficulty by recommending that infants weighing 2,500 g. or less at birth should be described as "infants of low birth weight". Currently two main sub-groups are being differentiated-those who are born early and are therefore truly immature and those who are poorly grown or "small for dates". Many of the latter are more mature at birth than their small size would indicate and should not therefore be included under the general term "immature" as has recently been proposed by Yerushalmy, van den Berg, Erhardt and Jacobziner (1965). As knowledge increases there is little doubt that further 
division into sub-groups will become possible on the basis of maturity at birth, foetal growth, and other indices. The factors influencing maturation have recently been reviewed and new methods being developed for measuring the physical characteristics of maturity may prove useful in identifying different groups of low birth weight babies (Mitchell and Farr, 1965). Thus more precise definition of infants at risk and increasing knowledge about the nature of the risks and the means of preventing them are combining to hold out real hope of substantially reducing the numbers of children with syndromes of cerebral dysfunction.

\section{Myelomeningocele and Hydrocephalus}

Two-thirds of all major congenital malformations causing perinatal death affect the central nervous system (Butler and Bonham, 1963) and the increasing survival of infants with myelomeningocele and/or hydrocephalus constitutes a growing medical, educational and social challenge. This type of congenital abnormality is not only common, occurring in some areas as often as 3 or 4 times in every 1,000 births (Smithells and Chinn, 1965), but is one of the few that are strongly familial (Record and McKeown, 1950). Thus the probability that a subsequent sibling will also be affected by a major malformation of the central nervous system is estimated by Lorber (1965) to be 1 in 14, as compared with approximately 1 in 200 for the general population.

The improved prospects for these infants result from a more optimistic outlook, based on advances in technical methods of treatment, longer life expectancy due to antibiotics and better facilities for care and education. The controversy about the urgency of immediate treatment following birth is not yet resolved (Zachary, 1965; Smith, 1965) but early surgical treatment of the lumbo-sacral myelomeningocele, together with insertion of a Holter valve if there is increasing hydrocephalus, is now fairly general practice in cases where function of the lower limbs and sphincters is reasonably good and there are no major associated malformations. However, the combination of flaccid paralysis of the lower limbs, perhaps with talipes and dislocated hips, incompetent sphincters and an abnormal cranium still raises doubts in many paediatricians' minds about the ethics of radical therapeutic measures. Despite such reservations, it is probable that many more of these infants are now being treated, because it is impossible to tell which infant will survive if untreated, and the ultimate handicap in such ohildren is far worse than if early treatment had been instituted.

This more positive approach to the myelomeningocele problem has created a whole host of new possibilities, ranging from the apparently normal child who lives on the brink of valve blockage and whose every headache or vomit causes consternation, to the child who is grossly deformed, incontinent and untrainable. Between these extremes there are large numbers of children who are virtually normal from the waist up, but whose misshapen lower limbs and difficulties with bowel and bladder control constitute a double handicap which is especially distressing and embarrassing to the child of good intelligence. Much can be done for these children by a planned programme of habilitation including full urological investigation and appropriate treatment (Smith, 1965), orthopaedic supervision of ambulation and care of the bowels, in addition to the general provision necessary for the handicapped child. In most cases, there is little justification for assuring the parents that the outlook is hopeless or that treatment is a waste of time because the child will soon die. Though some of these children do indeed die in early childhood from the effectso of increasing hydrocephalus, urinary tract complications or intercurrent infection, moderne comprehensive management enables as many as two out of three to survive. The majority of these will be handicapped but the handicap will be of far less degree than would have been the case had they survived untreated.

\section{Cardio-respiratory Disorders}

Diseases of the heart and lungs once headed the list of causes of chronic disability in childhood and, although their relative importance has diminished, they still rank high among the handicapping disorders of early life. Rheumatic heart disease has ceased to dominate the scene and the spotlight has shifted to children with congenital cardiac malformations, whose survival after major surgical procedures has created a new category of chronic handicap. Pulmonary tuberculosis and empyema are much less common than formerly and now seldom become chronic if properly treated by modern methods, but bronchiectasis and cystic fibrosis are still a problem and asthma appears to be becoming even more frequent, being now the most common form of chronic pulmonary handicap.

\section{Asthma}

Asthma occurs frequently in childhood and has become one of the principal reasons for 
admission of children to hospital (Sheldon, 1958). The community study in Tecumseh, Michigan (Broder, Barlow and Horton, 1962) showed that confirmed asthma affected about 4 per cent of the child population, while no less than 12 to 14 per cent had clinical manifestations which were probably asthmatic. Morrison Smith (1961) found that in Birmingham the prevalence of asthma among boys aged 5 to 6 years was 2.58 per cent, with an overall prevalence among schoolchildren of both sexes of 1.76 per cent. He commented that some very mild cases might have been missed, so the true prevalence is likely to have been somewhat higher. Preliminary results of a survey currently being made indicate that asthma affects approximately 5 per cent of schoolchildren in A'berdeen. Many asthmatic children do, of course, lead comparatively unrestricted lives. Frequent absences from school and limitations on social activities may often be considered a nuisance rather than a handicap, though their effect on the child's education and emotional development should not be too lightly dismissed. More severe degrees of the disorder affect the whole life of the child and his family, constituting a continuing disability which can only partially be ameliorated by treatment. The use of adrenal steroid hormones has a dramatic effect in enabling children to lead comparatively normal lives, and small doses can be taken for long periods without apparent adverse effect. Nevertheless, the possibility of complications such as adrenocortical atrophy, retardation of linear growth, osteoporosis and peptic ulceration cannot be disregarded and the use of these powerful hormones should be limited to a carefully selected minority of severely affected patients.

The disappearance of asthma as a cause of chronic handicap must await a better understanding of its pathogenesis. Much research in this field has centred on elucidating the nature of tissue sensitization and the role of chemical mediators (Aas, 1965). It is known in general terms that an antigen-antibody reaction is followed by the release of pharmacologically active substances from tissue mast cells and that these are responsible for at least some of the manifestations of asthmatic attacks. Prominent among these substances is histamine, whose participation in human asthma thas been established beyond doubt by the work of Schild, showing that when the specific antigen to which a patient is sensitive is applied to bronchial tissue removed at operation, histamine is released and causes the bronchial muscle to contract (Schild, Hawkins, Morgan and Herxheimer, 1951). Nevertheless, the mechanism of its action in the human body is still poorly understood and reliable experimental evidence of the part it plays is meagre (Code, Hurn and Mitchell, 1964). Other pharmacologically active substances such as SRS (slowreacting substance), bradykinin and possibly 5-hydroxytryptamine may also have a place in the genesis of asthma. Much has still to be learned about the physiopathology of human allergy before the possibility of prevention becomes a reality.

\section{Bronchiectasis}

The decline in prevalence of the classical form of bronchiectasis with emaciation, thick green sputum and foetor oris had led to the widely held belief that this disease is no longer of importance, but lesser degrees of the condition are more common than is generally realized and may be a cause of continuing disability, often slight but sometimes a considerable handicap. A study of bronchiectasis in the Northeast of Scotland (Clark, 1963) showed an average annual incidence of discovered bronchiectasis of 1.06 per 10,000 of the child population and, on this basis, approximately 1,000 new childhood cases should be recognized each year in Great Britain.

The degree of disability among Clark's 116 patients varied greatly but 35 were reported to be incapacitated several times each year from acute episodes of infection. In her study of 225 cases, Field (1961) found that the disability of childhood bronchiectasis tended to diminish in the second decade of life and that on the whole the activity of the adolescent bronchiectatic is not impaired, though some complain that running makes them cough and the majority take sedentary jobs. As the adolescent emerges into adult life, however, the symptoms may become increasingly troublesome again. Field comments on the severe handicap imposed by the association of bronchiectasis with asthmatic symptoms, which usually leads to death in early adult life.

It is important to realise that bronchiectasis may be a progressively spreading disease, with consequent increasing disability. Of 79 children who had bronchography repeated after an interval, $15 \mathrm{had}$ evidence of spread of the disease to previously unaffected segments (Clark, 1963). While efficient postural drainage combined with intelligent use of antibiotics will keep most bronchiectatic children in reasonable health, resection of the affected segments is advisable in 
the majority of cases, but operation is best deferred to late childhood or early adolescence when post-operative complications are less troublesome (Clark, 1964).

\section{Cystic Fibrosis}

The clinical manifestations of cystic fibrosis include chronic cough with difficult expectoration, repeated respiratory tract infections, cardiac insufficsency, foul-smelling diarrhoea and malnutrition with stunting of growth, so that the total disability is often severe. It is one of the tragic elements in this disease, as in myelomeningocele, that it often affects more than one sibling in a family, and the consequent disruption of family life can be very great. Formerly most children with cystic fibrosis died in infancy or early childhood, but with greater numbers now surviving into adolescence or adult life, this disease is likely to contribute more to the sum total of handicap in the community. Schwachman and his colleagues (1965) have recently reported on 65 patients with cystic fibrosis over the age of 17 years, the oldest being nearly 33 years of age. Most of these patients were comparatively mildly affected, representing only $3 \frac{1}{2}$ per cent of the total number of patients with cystic fibrosis observed at Boston Children's Hospital (McIntosh, 1965), and yet at least ten of them were limited in their activities, unable to hold a full-time job and tiring easily on exertion. Many severely affected children still die in childhood after a life of increasing invalidism, but a vigorous programme of treatment started as early as possible can do much to prolong life and minimise the disability, allowing children to lead relatively normal lives at least for a period.

\section{Other Handicapping Disorders}

An important cause of chronic handicap in childhood is accidental injury, which may create disabilities of many different kinds depending on the nature of the accident. In most cases, however, the effect is localized and can be minimized by prompt and continuing treatment, so that the ultimate handicap is often small unless brain damage has occurred. Progressive disorders of the locomotor system, such as muscular dystrophy, are fortunately rare, although they may cause serious handicap in a small number of children.

Almost any of the major chronic diseases may constitute a handicap to some patients but in many of them ultimate cure may be anticipated, while in others proper management may diminish the disability to the point where it is no longer a handicap. Well-controlled diabetes may be compatible with a completely normal life whereas poor control may cause disruption of school and social activities by frequent admission to hospital, or may even necessitate institutional care (Farquhar, 1962). The nephrotic syndrome, once a cause of invalidism in those children who did not die from the disease, can usually be managed well enough to allow the child to lead a normal or near-normal life. What Arneil (1963) called the "brine-logged, infection-ridden invalid" is now seldom encountered, and three out of four patients may now be expected to recover completely.

Coeliac disease and rheumatoid arthritis are other examples of diseases now amenable to treatment which only rarely cause persisting handicap.

\section{The Handicapped Child}

The many widely-differing conditions mentioned above have one thing in common-each may produce disability which prevents a child from leading a normal life and necessitates special medical, educational and social arrangements, i.e. constitutes a chronic handicap. The child may be able to compensate for his disability and consequently may appear to be coping adequately with the demands of every-co day life, but in doing so he may use up far? more energy than the normal child, which is not then available for other activities. This constitutes a hidden form of handicap, since compensating for the disability absorbs all his attention, taxes every effort and leaves no reserve of energy to meet new or unexpected demands. When compensation fails, the child is manifestly inadequate in one or more respects but may in addition have other concealed handicaps which must be sought out and allowed for. Assessment of the handicapped child includes not merely recognition of his limitations but also evaluation of his capabilities and other assets and estimation of his probable needs. Only by continuing assessment with frequent re-appraisal can the provision appropriate to the individual child be properly determined.

Consideration should be given not only to those needs which are common to all children, and to the special requirements imposed by the disabilities, but also to the extra needs which arise by virtue of the fact that the child is handicapped. Thus, for example, parent counselling becomes of especial importance because far more is required of the parents of a handicapped child than of the parents of a normal 
child. Parents have to be taught how to anticipate their child's needs, how to enlarge his experience which will otherwise be restricted by his disability and how to meet the difficulties raised by his growing awareness of his own limitations.

It will be apparent that many different medical, educational and social agencies must participate in planning the child's future and the co-ordination of their activities is a major operation for which the pattern of child care in this country is as yet poorly developed. The efforts of many organizations in drawing attention to the special requirements of children with certain kinds of disability are admirable as a means of marshalling resources for these children but may lead to unnecessary duplication and overlapping of provision and even on occasion to conflicts of interests. It must not be forgotten that whatever the nature of their disorder, they are all children and all handicapped, and their needs as handicapped children transcend in importance the special needs imposed by the particular form of disability. Recognition that the problem of child handicap in a community must be considered as a whole is fortunately growing, and present interest in possible ways of integrating services, manifest in such publications as the Scottish Report on the Young Chronic Sick (1964), together with increasingly widespread appreciation of the difficulties to be overcome, augur well for the future of the young handicapped child in Britain.

\section{REFERENCES}

AAS, K. (1965): Modern Concepts of Allergology, Acta pacdiat. (Uppsala), 54, 474.

Abercrombie, M. L. J. (1964): Perceptual and Visuomotor Disorders in Cerebral Palsy. Clinics in Developmental Medicine No. 11. London: Spastics Society/Heinemann.

Arneil, G. C. (1963): The Syndrome of Proteinuria. The Nephrotic Syndrome, Amer. Heart J., 65, 723.

BAX, M. C. O., and MAC KeITH, R. C. (1963): Minimal Cerebral Dysfunction. Clinics in Developmental Medicine No. 10. London: Spastics Society/ Heinemann.

BIRCH, H. G. (1964): The Problem of "Brain Damage" in Children in Brain Damage in Children. Edit. H. G. Birch. Baltimore: Williams and Wilkins.

Broder, I., Barlow, P. P., and Horton, R. J. M. (1962): The Epidemiology of Asthma and Hay Fever in a Total Community, Tecumseh, Michigan, J. Allergy, 33, 513 .

Brown, R. J. K., and Wallis, P. G. (1963): Hypoglycaemia in the Newborn Infant, Lancet, i, 1278.

Butler, N. R., and Bonham, D. G. (1963): Perinatal Mortality. Edinburgh: E. \& S. Livingstone.

Clark, N. S. (1963): Bronchiectasis in Childhood, Brit. med. J., i, 80.
Clark, N. S. (1964): Mechanism and Management of Childhood Bronchiectasis in Biochemical Clinics No. 4. The Lung. New York: Donnelley.

Code, C. F., Hurn, M. M., and Mitchell, R. G. (1964): Histamine in Human Disease, Proc. Mayo Clin., 39, 715 .

Denhoff, E., and Robinault, I. P. (1960): Cerebral Palsy and Related Disorders. New York and London: McGraw-Hill.

Drillien, C. M. (1964): The Growth and Development of the Prematurely Born Infant. Edinburgh: E. \& S. Livingstone.

FARquhar, J. W. (1962): Diabetic Children in Scotland and the Need for Care, Scot. med. J., 7, 119.

Field, C. E. (1961): Bronchiectasis, Arch. Dis. Childh., 36, 587.

Galloway, W. H. (1962): Late Manifestations of Meningitis, Curr. Med. Drugs., 3, 19.

Galloway, W. H. (1966): Acute Pyogenic Meningitis in the North-east of Scotland, Scot. med. J., 11, 119.

Gubbay, S. S. Ellis, E., Walton, J. N., and Court, S. D. M. (1965): Clumsy Children-a Study of Apraxic and Agnosic Defects in 21 Children, Brain, 88, 295.

Harrison, H. E., and Finberg, L. (1959): Hypernatremic Dehydration, Ped. Clin. N. Amer., 6, 193

Hatton, D. A. (1966): The Child with Minimal Cerebral Dysfunction, Develop. Mcd. Child Neurol., 8, 71 .

Hyman, C. B., Keaster, J., Hanson, V., Harris, I., SEDGWICK, R., and Wright, A. R. (1965): Relationship of Neonatal Hyperbilirubinaemia to Neurologic Residuals in 372 children followed at least 4 Years, J. Pediat., 67, 910.

Ingram, T. T. S., JAmESON, S., ERrington, J., and Mitchell, R. G. (1964): Living with Cerebral Palsy. Clinics in Developmental Medicine No. 14. London: Spastics Society/Heinemann.

JACKSON, A. D. M. (1965): Meningitis, Medical Annual, 1965 p.128. Bristol: John Wright.

JoHnson, E. W., Gove, R., and Ostermeier, B. (1963): The Value of Functional Training, Amer. J. ment. Defic., 67, 860 .

Kershaw, J. D. (1961): Handicapped Children. London: Heinemann.

LORBER, J. (1965): The Family History of Spina Bifida Cystica, Pediatrics, 35, 589.

MCDonald, A. D. (1962): Neurological and Ophthalmic Disorders in Children of Very Low Birth Weight, Brit. med. J., i, 895.

McDonald, A. D. (1963): Cerebral Palsy in Children of Very Low Birth Weight, Arch. Dis. Childh., 38, 579.

McInTOSH, R. (1965): Progress in Cystic Fibrosis, Pediatrics, 36, 673.

Mitchell, R. G. (1961): in Cerebral Palsy in Childhood and Adolescence. Edit. J. L. Henderson. Edinburgh: E. \& S. Livingstone.

Mitchell, R. G. (1965): Intraventricular Haemorrhage, Develop. Med. Child Neurol., 7, 566.

Mitchell, R. G., and FARr, V. (1965): The Meaning of Maturity and the Assessment of Maturity at Birth. in Gestational Age, Size and Maturity. Edit. M. Dawkins and W. G. MacGregor. Clinics in Developmental Medicine No. 19. London: Spastics Society/Heiriemann.

Neligan, G. A., Robson, E., and Watson, J. (1963): Hypoglycaemia in the Newborn: a Sequel of Intrauterine Malnutrition, Lancet, i, 1282. 
Paine, R. S. (1966): Neurological Grand Rounds: Minimal Chronic Brain Syndromes, Clin. Proc. Child. Hosp. (Wash.), 22, 21.

ReCORD, R. G., and MCKeOWN. T. (1950): Congenital Malformations of Central Nervous System: Maternal Reproductive History and Familial Incidence, Brit. J. Soc. Med., 4, 26.

Reid, D. H. S., and Tunstall, M. E. (1965): Recurrent Neoratal Apnoea, Lancet, ii, 155.

Reid, D. H. S., and Tunstall, M. E. (1966): The Respiratory Distress Syndrome of the Newborn, Anaesthesia, 21, 72.

Reid. D. H. S., Tunstall, M. E., and Mitchell, R. G. (1966): Neonatal Apnoeic Oxygenation, Brit. J. Anaesth., 38, 160.

Repont of a sub-committee appointed by the Scottish Health Services Council (1964): The Young Chronic Sick. Edinburgh: H.M.S.O.

RuSsell, G., and MCKay, E. (1966): Observations on Blood Glucose Concentration in the Perinatal Period, Arch. Dis. Childh. (in the press).

SChILd, H. O., Hawkins, D. F., Mongar, J. L., and HERXHEIMER, H. (1951): Reactions of Isolated Human Asthmatic Lung and Bronchial Tissue to a Specific Antigen: Histamine Release and Muscular Contraction, Lancet, ii, 376.

ShEldon, W. (1958): The Changing Emphasis in Paediatrics in The Medicai Annual 1958. Bristol: John Wright.
Schwachman, H., KulczycKı, L. L., and KHaW, K.-T. (1965) : Studies in Cystic Fibrosis, Paediatrics, 36, 689.

Smallpiece, V., and Davies, P. A. (1964): Immediate Feeding of Premature Infants with Undiluted Breast Milk, Lancet, ii, 1349.

Smith, J. M. (1961): Prevalence and Natural History of Asthma in Schoolchildren, Brit. med. J., i, 711.

SMith, E. D. (1965): Spina Bifida and the Total Care of Spinal Myelomeningocele. Springfield, Illinois: Charles C. Thomas.

Smithells, R. W., and ChinN, E. R. (1965): Spina Bifida in Liverpool, Develop. Med. Child. Neurol., 7, 258.

Strang, L. B. (1965): The Lungs at Birth, Arch. Dis. Childh., 40, 575.

Talbot, N. B. (1965) : Paediatric Frontiers in Developmental Medicine, Amer. J. Dis. Child., 110, 287.

Wharton, B. A., and Bower, B. D. (1965): Immediate or Later Feeding for Premature Babies?, Lancet, ii, 969.

Yerushalmy, J., VAN DEN Berg, B., ERhardt, C. L., and JACOBZINER, H. (1965): Birth Weight and Gestation as Indices of "Immaturity", Amer. J. Dis. Child., 109, 43.

ZACHARY, R. B. (1965): Early Neurosurgical Approaches to Spina Bifida, Develop. Med. Child Neurol., 7, 492.

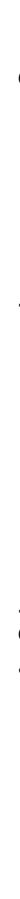

